\title{
Sex differences and similarities in preferred mating arrangements
}

\author{
EMILY A. STONE, AARON T. GOETZ, \& \\ TODD K. SHACKELFORD
}

Florida Atlantic University, USA

\begin{abstract}
Over $90 \%$ of men and women marry, but as many as $50 \%$ of married men and women have affairs. Thus, in a self-reported study of ideal mating arrangements, in which costs associated with infidelity are eliminated, it was hypothesized that men and women would prefer a mating arrangement of monogamy with the option of casual, extra-pair sex. Unexpectedly, men and women $(n=463)$ overwhelmingly preferred strictly monogamous mating arrangements when forced to select one such ideal arrangement. A hypothesized sex difference did emerge, however, with men more than women rating as more interesting those arrangements that included casual sex or partner variety. The discussion addresses several evolutionarily plausible accounts for the current results, and integrates the current results with existing theories about sex differences and similarities in mating psychology and behavior.
\end{abstract}

Keywords: Ideal mating arrangements, mating strategies, sex differences, sex similarities, evolutionary psychology

\section{Introduction}

In popular culture, when a man announces his plans to marry, often a male friend of his will remind him of the defining feature of monogamy which, paradoxically, also may be its greatest cost-that the man will have sex only with this one woman for the rest of his life (or the length of the relationship). A monogamous mating strategy can be beneficial, but is 
inherently restrictive. Monogamy, defined as a prolonged association and exclusive mating relationship between one man and one woman (Wittenberger \& Tilson, 1980), may have solved several problems our ancestors likely faced, such as paternity uncertainty, ensuring that offspring reach reproductive maturity, and preventing a mate's infidelity. Indeed, monogamous mateships do appear to afford reproductive benefits to men and women, as the presence of a father has been shown to decrease child mortality rates in developing countries in South America, Africa, and Asia, and among the Ache of Paraguay (Hurtado \& Hill, 1992; United Nations, 1985).

Despite the benefits that a monogamous mating strategy may provide, not all men and women are able to keep this commitment. Over $90 \%$ of men and women marry at some point in their lives (Epstein \& Guttman, 1984), but infidelity rates range from 15 to $50 \%$ for women and from 25 to $50 \%$ for men (e.g., Simmons, Firman, Rhodes, \& Peters, 2004). As such, it appears that men and women may pursue extra-pair copulations when given the chance; opportunity appears to be a key predictor of infidelity (see Buss, 2003).

Ancestral women who sometimes pursued a monogamous mateship but with extra-pair copulations may have benefited by securing "good genes" for their offspring, exchanging sex for resources and protection, and acquiring a better mate-benefits that a monogamous mating strategy alone could not provide (e.g., Greiling \& Buss, 2000; Zeh \& Zeh, 2001). Ancestral men who pursued extra-pair copulations might have benefited by their potential to sharply increase a man's reproductive success: a married man with two children by his wife could increase his reproductive success by $50 \%$ by producing one child through an extra-pair partner (Symons, 1979). Extrapair copulations have the potential to directly benefit men's reproductive success and, as such, men are predicted to be especially sensitive to opportunities for extra-pair copulations.

There are costs, of course, associated with pursuing extra-pair copulations. Women risk contracting a sexually transmitted disease, battery by a jealous mate, and losing the resources of her primary mate (Daly \& Wilson, 1988; Greiling \& Buss, 2000). Costs to men include contracting a sexually transmitted disease and suffering violence at the hands of jealous mates (Daly \& Wilson, 1988). Despite these costs, both men and women are hypothesized to select an arrangement of monogamy with the option of having extra-pair copulations as their ideal mating arrangement. As $15-50 \%$ of married men and women appear to actually pursue this strategy, and as the questions in this study are about ideal situations in which potential costs have been eliminated, we expect far greater numbers of men and women to express an interest in this arrangement. The costs of engaging in extra-pair copulations are presumably a large factor inhibiting more men and women from pursuing extra-pair copulations. This study eliminates that barrier, potentially allowing for men and women to derive pure benefits from this combination of short-term and long-term mating strategies. 
Hypothesis 1: Men and women will select a monogamous mating arrangement with the option of casual, extra-pair sex as preferable to other mating arrangements.

Many factors (unconsciously) influence mating decisions, however. One factor is the parental investment necessary to produce and raise an offspring to reproductive maturity. Men and women differ in this respect, and it would be astounding if these differences had not affected human psychology over evolutionary time (Symons, 1979). The costs to an ancestral man who made a poor mating choice were minimal compared to the costs of a poor mating choice to a woman (e.g., pregnancy and the possibility of raising a child alone). As predicted by the theory of parental investment (Trivers, 1972), a result of this difference between the sexes is that females are more often the "choosier" sex and males usually compete for sexual access to females. This differential minimum parental investment has affected men's and women's mating strategies such that men and women are today designed to minimize costs and maximize benefits accordingly. Men who pursued mating arrangements and strategies that included casual sex with a variety of women might have experienced relatively greater reproductive success than men who did not pursue such arrangements and strategies (Buss, 2003; Symons, 1979). The equivalent cannot be said of women, as an ancestral woman who casually mated with a variety of men would likely have produced fewer offspring than a man who mated with as many women in the same time period. It therefore has been predicted and documented that men are more psychologically attuned to, and interested in, opportunities for casual mating, than are women (see Buss, 2004, for a review).

Most men and women must make compromises in sexual strategy in order to mate. As women are the choosier sex, monogamy is often a strategy that men pursue to attract, secure, and maintain sexual partners. In addition, men may reap reproductive rewards by monogamous investment in a woman and the children they share with her. And yet, men may retain a greater preference than women for casual sex, as evidenced by sex differences in fantasy (Ellis \& Symons; 1990; Leitenberg \& Henning, 1995), mate preferences (Buss, 1989, 2003), number of sexual partners desired (Schmitt, 2003), and interest in pursuing casual sex (Clark \& Hatfield, 1989; Schmitt, Shackelford, Duntley, Tooke, \& Buss, 2001).

These desires for casual sex and partner variety are expected to translate into actual mating behavior, and previous work indicates that this is the case. Rates of infidelity are higher for men (Buss, 2003), and men appear to have greater intrinsic sexual motivation than women (Baumeister, Catanese, \& Vohs, 2001; Okami \& Shackelford, 2001). Regardless of whether they are pursuing a short-term, long-term, or mixed mating strategy, men more than women are hypothesized to report a greater interest in mating arrangements that include elements of casual sex and partner variety.

Hypothesis 2: Men more than women will rate as more interesting those mating arrangements that include elements of casual sex and partner variety. 
Ideal preferences, much like fantasy, may provide insight into the operation of the psychological mechanisms that motivate and direct the sexual strategies of men and women (Ellis \& Symons, 1990). To gain insight into the mating arrangements that men and women prefer, unconstrained by reality, we collected self-report data from several hundred men and women. We first asked participants to choose the mating arrangement they preferred, and then we asked them to rate each mating arrangement according to their interest in participating in that arrangement.

\section{Method}

\section{Participants}

Participants were 206 men (mean age $=20.5$ years, $S D=4.8$ ) and 257 women (mean age $=21.2$ years, $S D=5.8$ ) who completed a survey designed for this study. We recruited participants from college campuses. Participants received research credit in partial fulfillment of a course requirement in exchange for their participation. About half of the sample $(49.2 \%)$ was of non-European decent, reflecting the ethnic diversity of the local population.

\section{Materials and procedures}

Questions on the survey manipulated varying degrees of monogamy, partner variety, and casual sex, as well as sexual behavior options, such as fidelity and infidelity. Monogamy was described as "faithful marriage to one partner"; interest in casual sex was gauged by the descriptive "freedom to have temporary, 'casual' sex partners whenever you felt like it'. To separate desire for partner variety from the element of casual sex, we include several options of long-term partner variety, i.e., "faithful initial marriage to 2 or 3 partners, but with the option of adding new partners to the marriage every so often, with a limit of 10 total spouses". These elements combined to produce a sampling of eight different mating arrangements with varying degrees of commitment and partner variety (see Table I). The survey also asked participants to imagine each of these arrangements to be "equally moral, socially acceptable, and practically feasible", to eliminate potential costs that might realistically accompany these mating arrangements, and hence enable participants to imagine their ideal arrangement. The first part of the survey asked participants to select the mating arrangement that best described their "ideal" mating arrangement. The second part of the survey asked participants to rate their amount of interest in each of the eight arrangements (on a scale of 0 to 9 , where $0=$ not at all interested, and $9=$ extremely interested). Participants completed the survey in a group setting, and placed the survey in a brown security envelope upon completion.

\section{Results}

The majority of men and women selected "faithful marriage to one partner" as their ideal mating arrangement $(78.0 \%$ and $84.8 \%$, respectively). 
Table I. Sex differences and similarities in ideal choice and ratings of mating arrangements.

\begin{tabular}{|c|c|c|c|c|c|c|}
\hline \multirow[b]{2}{*}{ Mating arrangement } & \multicolumn{2}{|c|}{$\begin{array}{c}\text { Ideal choice } \\
(\%)\end{array}$} & \multicolumn{2}{|c|}{$\begin{array}{l}\text { Mean rating } \\
\quad(S D)\end{array}$} & \multirow[b]{2}{*}{$t$} & \multirow[b]{2}{*}{$d$} \\
\hline & Men & Women & Men & Women & & \\
\hline (1) Faithful marriage to one partner & 78.0 & 84.8 & $\begin{array}{l}8.26 \\
(1.57)\end{array}$ & $\begin{array}{c}8.52 \\
(1.50)\end{array}$ & -1.74 & -0.17 \\
\hline $\begin{array}{l}\text { (2) Marriage to one partner, with freedom } \\
\text { to have casual sex partners }\end{array}$ & 13.4 & 9.5 & $\begin{array}{c}4.23 \\
(3.41)\end{array}$ & $\begin{array}{l}3.06 \\
(3.33)\end{array}$ & $3.52^{\star \star}$ & 0.35 \\
\hline (3) Faithful marriage to two or three partners & 1.6 & 0.9 & $\begin{array}{c}2.69 \\
(2.86)\end{array}$ & $\begin{array}{l}1.67 \\
(2.65)\end{array}$ & $3.78^{\star \star}$ & 0.37 \\
\hline $\begin{array}{l}\text { (4) Marriage to two or three partners, with } \\
\text { freedom to have casual sex partners }\end{array}$ & 2.2 & 1.3 & $\begin{array}{l}2.06 \\
(2.56)\end{array}$ & $\begin{array}{l}0.99 \\
(1.90)\end{array}$ & $4.93^{\star \star}$ & 0.48 \\
\hline $\begin{array}{l}\text { (5) Faithful initial marriage to two or three } \\
\text { partners, with option of adding } \\
\text { limit of ten new marriage partners }\end{array}$ & 0.5 & 0.4 & $\begin{array}{c}1.71 \\
(2.35)\end{array}$ & $\begin{array}{c}0.73 \\
(1.66)\end{array}$ & $4.99^{\star \star}$ & 0.48 \\
\hline $\begin{array}{l}\text { (6) Marriage to limit of ten partners, with } \\
\text { freedom to have casual sex partners }\end{array}$ & 1.1 & 0.0 & $\begin{array}{c}1.31 \\
(2.08)\end{array}$ & $\begin{array}{c}0.45 \\
(1.28)\end{array}$ & $5.21^{\star \star}$ & 0.50 \\
\hline $\begin{array}{l}\text { (7) No marriage, with freedom to have as } \\
\text { many casual sex partners as you } \\
\text { could attract }\end{array}$ & 3.2 & 1.7 & $\begin{array}{l}3.60 \\
(3.24)\end{array}$ & $\begin{array}{c}1.93 \\
(2.70)\end{array}$ & $5.75^{\star \star}$ & 0.56 \\
\hline (8) No marriage AND no sex at all & 0.0 & 0.9 & $\begin{array}{c}0.43 \\
(1.54)\end{array}$ & $\begin{array}{c}0.78 \\
(1.98)\end{array}$ & $-1.98^{\star \star \star}$ & -0.20 \\
\hline
\end{tabular}

*Ideal choice is the percentage of participants who selected each arrangement as their ideal mating arrangement. Mean ranking is based on a scale of 0 to 9 , where $0=$ not at all interested and $9=$ extremely interested. For all $t$-tests, $d f=418 . d=$ effect size index $d$ (Cohen, 1988).

$\star \star p<0.001$.

$\star \star \star p<0.05$.

A chi-square test of independence for men's and women's ideal mating arrangement yielded a non-significant result $\left[\chi^{2}(8)=8.81, p>0.05\right]$. Thus, Hypothesis 1 was not supported: Men and women clearly did not select a monogamous mating arrangement with the option of casual, extra-pair sex, as preferable to other mating arrangements (see Table I).

The results of $t$-tests comparing ratings provided for each of the arrangements indicated that men and women differed significantly on all but one arrangement: "faithful marriage to one partner". Both men and women rated this arrangement of extreme interest (see Table I). These data also failed to support Hypothesis 1, as men and women did not select monogamy with the option of casual sex as their ideal mating arrangement, but rather indicated an equally intense interest in a strictly monogamous mating arrangement.

Men and women rated the remaining seven arrangements differently (see Table I). Consistent with Hypothesis 2, men were significantly more interested than women in arrangements that included elements of casual sex and partner variety. Women were significantly more interested in the only arrangement void of any elements of casual sex, partner variety, and monogamy, but were still not particularly interested in this arrangement $(M=0.78)$. For all statistically significant differences, effect sizes ranged from small to medium (see Table I). After we instituted a Bonferroni correction to control for alpha inflation (reducing $p$ from 0.05 to $0.05 / 8$ or 0.006 ), 
the final arrangement, void of elements of sexuality, no longer generated a significance difference between the sexes. Sex differences along the other six arrangements remained significant, illustrating the robustness of these differences.

\section{Discussion}

Men and women overwhelmingly preferred a lifelong, strictly monogamous mating arrangement, a result that was inconsistent with Hypothesis 1, which stated that men and women will select a monogamous mating arrangement with the option of casual, extra-pair sex, as preferable to other mating arrangements. Men and women did not differ in this preference for a monogamous mating arrangement, and both rated it of extreme interest. The results of this study are consistent with Hypothesis 2, and indicate that, although men and women are equally very interested in a monogamous mateship, men are significantly more interested than women in arrangements that include opportunities for casual sex and partner variety.

The current results indicating sex differences in interest in casual sex and partner variety are consistent with previous research. Men are not only more approving of casual sex (Oliver \& Hyde, 1993), but also they are more likely to cite a wish to be able to have sex without commitment (Ehrlichman \& Eichenstein, 1992) than are women. In sexual fantasies, men fantasize about sexual encounters with a greater number of partners than do women (Ellis \& Symons, 1990); men are four times as likely as women to have imagined sexual encounters with over 1,000 different partners (Ellis \& Symons, 1990).

This preference for lifelong strict monogamy may be surprising in light of actual mating behavior. Estimates of infidelity rates for men and women are much greater than the $22.0 \%$ and $14.7 \%$ of men and women, respectively, who selected as "ideal" those arrangements that include elements of casual sex and partner variety. There appears to be a discrepancy between mating arrangement preferences and actual behavior. We next present four explanations that might account for why men and women idealize monogamous mating arrangements, yet appear to practice others.

Infidelity rates range from $12-50 \%$ for women with a median estimate of $30 \%$, and $25-50 \%$ for men with a median estimate of $40 \%$ (for reviews, see Gangestad \& Thornhill, 1997; Simmons et al., 2004). Accordingly, about $60 \%$ of men and $70 \%$ of women remain faithful to their partners. These percentages of actual monogamy are somewhat close to the preferred monogamy percentages found in the current study $(78 \%$ of men and $85 \%$ of women). The current finding that the majority of men and women idealize faithful marriage to one partner might reflect the fact that the majority of men and women maintain a faithful marriage to one partner. This would imply that a strong predictor of men's and women's future infidelity is their choice of an ideal mating arrangement. Such a simple predictor of infidelity would be astonishing and, thus, warrants future investigation. 
Alternatively, perhaps there exists a preference mechanism idealizing monogamy that serves to aid the concealment of future infidelities. Because this preference mechanism for monogamy appears to be an active misrepresentation of reality to the conscious mind, it may be thought of as a selfdeception mechanism (Trivers, 2000). It is easier to deceive someone (and to avoid being detected) if you have deceived yourself in the process (Trivers, 2000). By projecting a false preference for monogamy, one may better deceive a partner about extra-pair copulation intentions, lowering the likelihood of one's partner detecting an infidelity. This might explain why men and women idealize monogamous mating arrangements, yet have such high infidelity rates.

A third explanation for the current findings might be that, when considering their ideal mating arrangements, men and women assume that their partners would be afforded the same freedom associated with their selected mating arrangement and, thus, men and women avoided selecting as ideal any mating arrangement that would allow their partners to have casual sex partners or the option of adding new marriage partners, for example. Because the survey did not specify which mating strategy the "ideal" partner(s) would pursue, perhaps men and women believed that if they selected "Marriage to one partner, with freedom to have casual sex partners", then their ideal partner also would be permitted the freedom to have casual sex partners. Thus, men and women may have selected as their ideal mating arrangement a faithful marriage to one partner to restrict their partners' sexual autonomy.

A fourth explanation may be that men and women preferred a monogamous mating arrangement because the costs associated with infidelities are too deeply engrained in human sexual psychology. Men and women may be unable to extricate the costs associated with infidelity from the benefits potentially gained in the ideal arrangements, and were thus less inclined to select them. Although we asked participants to imagine the mating arrangements to be "equally moral, socially acceptable, and practically feasible", their responses may not have been influenced by this evolutionarily novel qualification.

Although we present four separate explanations that might account for why men and women idealize monogamous mating arrangements yet practice others, the explanations may not be mutually exclusive. Also, the mating arrangements included in this study were meant to be a sampling of different types of possible mating arrangements. Future studies could investigate other arrangements not included in this study, such as a preference for maintaining a strictly casual sex relationship with one person.

Monogamy likely served as a solution to a host of problems associated with human reproductive success. Although monogamy may be the idealized mating arrangement of men and women, their behavior suggests that it is not the most commonly practiced arrangement. To answer the question why humans might idealize one strategy but practice a different strategy, further research is needed in self-deception, in the assumptions associated 
with selecting ideal mating arrangements, and in the ability to extricate the costs associated with infidelity.

\section{References}

Baumeister, R. F., Catanese, K. R., \& Vohs, K. D. (2001). Is there a gender difference in strength of sex drive? Theoretical views, conceptual distinctions, and a review of relevant evidence. Personality and Social Psychology Review, 5, 242-273.

Buss, D. M. (1989). Sex differences in human mate preferences: Evolutionary hypotheses tested in 37 cultures. Behavioral and Brain Sciences, 12, 1-49.

Buss, D. M. (2003). The evolution of desire (Rev. ed.). New York: Basic Books.

Buss, D. M. (2004). Evolutionary psychology (2nd ed.). Boston: Allyn \& Bacon.

Clark, R. D., \& Hatfield, E. (1989). Gender differences in receptivity to sexual offers. Fournal of Psychology and Human Sexuality, 2, 39-55.

Cohen, J. (1988). Statistical power analysis for the behavioral sciences (2nd ed.). Hillsdale, NJ: Erlbaum.

Daly, M., \& Wilson, M. (1988). Homicide. Hawthorne, NY: Aldine de Gruyter.

Ehrlichman, H., \& Eichenstein, R. (1992). Private wishes: Gender similarities and differences. Sex Roles, 26, 399-422.

Ellis, B. J., \& Symons, D. (1990). Sex differences in sexual fantasy: An evolutionary psychological approach. Fournal of Sex Research, 27, 527-555.

Epstein, E., \& Guttman, R. (1984). Mate selection in man: Evidence, theory, and outcome. Social Biology, 31, 243-278.

Gangestad, S. W., \& Thornhill, R. (1997). The evolutionary psychology of extrapair sex: The role of fluctuating asymmetry. Evolution and Human Behavior, 18, 69-88.

Greiling, H., \& Buss, D. M. (2000). Women's sexual strategies: The hidden dimension of extra-pair mating. Personality and Individual Differences, 28, 929-963.

Hurtado, A. M., \& Hill, K. R. (1992). Paternal effect on offspring survivorship among Ache and Hiwi hunter-gatherers: Implications for modeling pair-bond stability. In B. S. Hewlett (Ed.), Father-child relations (pp. 31-55). New York: Aldine de Gruyter.

Leitenberg, H., \& Henning, K. (1995). Sexual fantasy. Psychological Bulletin, 117, 469-496.

Okami, P., \& Shackelford, T. K. (2001). Human sex differences in sexual psychology and behavior. Annual Review of Sex Research, 12, 186-241.

Oliver, M. B., \& Hyde, J. S. (1993). Gender differences in sexuality: A meta-analysis. Psychological Bulletin, 114, 29-51.

Schmitt, D. P., \& 118 co-authors (2003). Universal sex differences in the desire for sexual variety: Tests from 52 nations, 6 continents, and 13 islands. Fournal of Personality and Social Psychology, 85, 85-104.

Schmitt, D. P., Shackelford, T. K., Duntley, J., Tooke, W., \& Buss, D. M. (2001). The desire for sexual variety as a key to understanding basic human mating strategies. Personal Relationships, $8,425-455$.

Simmons, L. W., Firman, R. C., Rhodes, G., \& Peters, M. (2004). Human sperm competition: Testis size, sperm production, and rates of extrapair copulations. Animal Behaviour, 68, 297-302.

Symons, D. (1979). The evolution of human sexuality. New York: Oxford University Press.

Trivers, R. (1972). Parental investment and sexual selection. In B. Campbell (Ed.), Sexual selection and the descent of man (pp. 136-179). Chicago: Aldine-Atherton.

Trivers, R. (2000). The elements of a scientific theory of self-deception. Annals of the New York Academy of Sciences, 907, 114-131.

United Nations. (1985). Socio-economic differentials in child mortality in developing countries. New York: Author.

Wittenberger, J. F., \& Tilson, R. L. (1980). The evolution of monogamy: Hypotheses and evidence. Annual Review of Ecology and Systematics, 11, 197-232.

Zeh, J. A., \& Zeh, D. W. (2001). Reproductive mode and the genetic benefits of polyandry. Animal Behaviour, 61, 1051-1063. 